\title{
Comparative study of acute in vitro and short-term in vivo triiodothyronine treatments on the contractile activity of isolated rat thoracic aortas
}

\author{
Ruth Mery López ${ }^{1}$, Jorge Skiold López ${ }^{2}$, Jair Lozano ${ }^{2}$, Héctor Flores ${ }^{3}$, Rosa Angelica Carranza ${ }^{4}$, Antonio Franco ${ }^{1}$, and \\ Enrique Fernando Castillo,* \\ ${ }^{1}$ Section of Postgraduate Studies and Research, Higher School of Medicine, National Polytechnic Institute, Mexico City 11340, Departments of ${ }^{2}$ Cellular \\ Biology and ${ }^{3}$ Inmuno-Biochemistry, National Institute of Perinatology, Mexico City 11000, ${ }^{4}$ Research Division, La Raza Medical Center, Mexican Instiitute of \\ Social Security, Mexico City 02990, Mexico
}

\section{ARTICLE INFO \\ Received March 4, 2020 \\ Revised April 14, 2020 \\ Accepted April 20, 2020 \\ *Correspondence \\ Enrique Fernando Castillo \\ E-mail: ecastilloh@ipn.mx}

Key Words

Genomic effect

Rapid non-genomic effect

Rat aorta

Triiodothyronine

\begin{abstract}
We aimed to characterize the participation of rapid non-genomic and delayed non-genomic/genomic or genomic mechanisms in vasoactive effects to triiodothyronine (T3), emphasizing functional analysis of the involvement of these mechanisms in the genesis of nitric oxide (NO) of endothelial or muscular origin. Influences of in vitro and in vivo T3 treatments on contractile and relaxant responsiveness of isolated rat aortas were studied. In vivo T3-treatment was $500 \mu \mathrm{g} \cdot \mathrm{kg}^{-1} \cdot \mathrm{d}^{-1}$, subcutaneous injection, for $1\left(\mathrm{~T}_{1 \mathrm{~d}}\right)$ and $3\left(\mathrm{~T}_{3 \mathrm{~d}}\right)$ days. In experiments with endothelium-intact aortic rings contracted with phenylephrine, increasing concentrations of T3 did not alter contractility. Likewise, in vitro T3 did not modify relaxant responses induced by acetylcholine or sodium nitroprusside (SNP) nor contractile responses elicited by phenylephrine or angiotensin II in endothelium-intact aortas. Concentration-response curves (CRCs) to acetylcholine and SNP in endothelium-intact aortic rings from $\mathrm{T}_{1 d}$ and $\mathrm{T}_{3 \mathrm{~d}}$ rats were unmodified. $\mathrm{T}_{3 \mathrm{~d}}$, but not $\mathrm{T} 3_{1 d}$, treatment diminished CRCs to phenylephrine in endothelium-intact aortic rings. CRCs to phenylephrine remained significantly depressed in both endothelium-denuded and endothelium-intact, nitric oxide synthase inhibitor-treated, aortas of $\mathrm{T}_{3 d}$ rats. In endotheliumdenuded aortas of $\mathrm{T}_{3 \mathrm{~d}}$ rats, CRCs to angiotensin II, and high $\mathrm{K}^{+}$contractures, were decreased. Thus, in vitro T3 neither modified phenylephrine-induced active tonus nor CRCs to relaxant and contractile agonists in endothelium-intact aortas, discarding rapid non-genomic actions of this hormone in smooth muscle and endothelial cells. Otherwise, $\mathrm{T3}_{3 \mathrm{~d}}$-treatment inhibited aortic smooth muscle capacity to contract, but not to relax, in an endothelium- and NO-independent manner. This effect may be mediated by delayed non-genomic/genomic or genomic mechanisms.
\end{abstract}

\section{INTRODUCTION}

Thyroid hormones (THs), 3,5,3',5' tetraiodo-L-thyronine (T4) and 3,5,3' triiodo-L-thyronine (T3), have important physiological and pathological effects on the cardiovascular system [1-4]. Excessive functional activity of the thyroid gland-hyperthyroid- ism-is characterized by an overstimulated cardiovascular state with increased heart rate, stroke volume, systolic blood pressure, pulse pressure, and decreased systemic vascular resistance (SVR) [1-4]. Conversely, a significant reduction in THs synthesis and release-hypothyroidism-results in decreased HR and stroke volume, increased SVR, diastolic hypertension, and lessened pulse

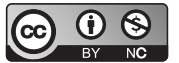

This is an Open Access article distributed under the terms of the Creative Commons Attribution Non-Commercial License, which permits unrestricted non-commercial use, distribution, and reproduction in any medium, provided the original work is properly cited. Copyright @ Korean J Physiol Pharmacol, pISSN 1226-4512, elSSN 2093-3827
Author contributions: R.M.L. and E.F.C. research design. R.M.L., J.S.L., J.L., H.F., R.A.C., A.F., and E.F.C. conducted experiments and performed data analysis. R.M.L. and E.F.C. wrote the manuscript. 
pressure [1-4].

THs exert their effects either per genomic mechanisms by binding to thyroid receptors (TR) inside the nucleus and regulating gene transcription, or through non-genomic mechanisms initiated outside cell nucleus at plasma membrane receptors and receptors located in the cytoplasm $[5,6]$. Several links have been recognized between non-genomic and genomic actions of THs (non-genomic/genomic mechanisms) [5,6].

Important reports indicate that THs can act directly on blood vessels causing smooth muscle depressor effects in an endothelium-dependent and -independent manner [7,8]. In isolated skeletal muscle resistance arteries of rats, T4 and T3 induced rapid onset ( $20 \mathrm{~min}$ ) vasodilator responses that were attenuated, but not abolished, with denudation or functional inhibition of the endothelium; implying that vasodilator responses to THs result of their combined effects on endothelium and smooth muscle [9]. In endothelium-denuded rat aortic rings, acute in vitro administration of $\mathrm{T} 3$ (30 $\mathrm{min}$ ) reduced phenylephrine (PHE)-induced vasoconstriction, and this effect was reversed by nitric oxide (NO) synthesis inhibitor, L-NAME; which denotes that T3 inhibits aortic contractile responses inducing smooth muscle synthesis of NO [10]. Together, these data $[9,10]$ exemplified the rapid nongenomic action of THs in isolated arteries. On the other hand, experimental hyperthyroidism induced by short-term T4 (3 days) and long-term T3 (6-12 weeks) treatments [11,12], provoked an increased relaxing effect of acetylcholine and a decreased contractile responses to norepinephrine in endothelium-intact rat aortic tissues; relaxant and contractile responses of isolated rat aortas were found modified by an increased endothelial vasodepressor function, elicited by THs effects pondered as genomic $[12,13]$. Contrariwise, abdominal aortas from long-term (6 weeks) hypothyroid rats were associated with diminished endotheliumdependent and -independent relaxations [14], indicating inhibition of vasomotor function through adaptations of both endothelial (ECs) and smooth muscle (SMCs) cells [14]. Noticeably, aortas from long-term (8-12 weeks) hypothyroid rats manifested a reduction in $\mathrm{NO}$ availability [15].

The following studies with ECs and SMCs cultures support the possibility of observing rapid non-genomic effects in isolated blood vessels. In SMCs isolated from rat aorta and cultured in a deformable matrix, T3 caused relaxation of these cells in $10 \mathrm{~min}$, suggesting its direct action by a rapid non-genomic mechanism [16]. In other study, acute administration of T3 increased the generation of NO in SMCs of rat aorta, resulting in a significant decrease in myosin light chain phosphorylation levels as indirect evidence of contractility inhibition; prominently, T3 augmented the expression of neuronal (nNOS), endothelial (eNOS), and inducible (iNOS) NO synthases, in $30 \mathrm{~min}$, through the activation of the phosphatidylinositol 3-kinase (PI3K)/protein kinase B (Akt) signaling pathway [10]. Otherwise, T3 activated eNOS (within 10-20 min) through PI3K/Akt in ECs from the bovine aorta and human umbilical vein [17].
SVR is decreased in experimental and clinical hyperthyroidism, and it is increased in THs deficiency [1-4]. However, the direct effects of THs on blood vessels have not been convincingly explained. The present work was designed to help characterize the participation of rapid non-genomic, and delayed genomic or non-genomic/genomic, mechanisms in THs-elicited vasodepressor effects; emphasizing the functional analysis of the involvement of these mechanisms in the genesis of $\mathrm{NO}$ of endothelial or muscular origin. We aimed to elucidate whether acute in vitro and short-term in vivo T3 treatments inhibit the development of active tonus in rat thoracic aortas by increasing the synthesis of NO in endothelium and/or smooth muscle.

\section{METHODS}

All experimental procedures were approved by the Animal Care and Use Committee of our Institution and complied with the Mexican Federal Regulations for Animal Experimentation and Care (NOM-062-ZOO-1999; Ministry of Agriculture, Mexico City, Mexico). Male Wistar rats (250-300 g body mass, 10-12 weeks old) were housed under controlled conditions $\left(22^{\circ} \mathrm{C} \pm 2{ }^{\circ} \mathrm{C}\right.$, $60 \% \pm 5 \%$ humidity, and $12 \mathrm{~h}$ light/dark cycle); normal chow and tap water were given ad libitum.

\section{Short-term in vivo T3 treatment}

Based on previous research [11], experimental hyperthyroidism was induced by subcutaneous injection of T3 $\left(500 \mu \mathrm{g} \cdot \mathrm{kg}^{-1} \cdot \mathrm{d}^{-1}\right)$ diluted in alkaline saline solution $(0.5 \mathrm{mM} \mathrm{NaOH}$ in $0.9 \% \mathrm{NaCl})$ for $1\left(\mathrm{~T} 3_{1 \mathrm{~d}}\right)$ and $3\left(\mathrm{~T}_{3 \mathrm{~d}}\right)$ days. Control animals were injected daily with the vehicle at the same volume $\left(1 \mathrm{ml} \cdot \mathrm{kg}^{-1}\right)$ for $1\left(\mathrm{~V}_{1 \mathrm{~d}}\right)$ and 3 $\left(\mathrm{V}_{3 \mathrm{~d}}\right)$ days. Experiments were performed $24 \mathrm{~h}$ after the last injection.

\section{Assessment of the hyperthyroid state}

Blood samples were collected without anticoagulant from abdominal aortas, centrifuged at $1,000 \mathrm{~g}$ for $10 \mathrm{~min}$ at $4^{\circ} \mathrm{C}$, and stored at $-20^{\circ} \mathrm{C}$ until assay. Levels of free T3 (fT3) and thyroidstimulating hormone (TSH) were determined in the serum of control and T3-treated rats using enzyme-linked immunosorbent assay (ELISA) kits (fT3; Monobind, Inc., Lake Forest, CA, USA; TSH; ALPCO, Salem, NH, USA) according to manufacturer specifications.

Besides, left ventricular dry mass (LVdM) to tibia length (TL) ratio, LVdM/TL (mg/mm), was used as an index of cardiac hypertrophy, regularly observed in hyperthyroid disorder [1-3]. Body mass was recorded every day. 


\section{Tension measurements}

Rats were anesthetized with pentobarbital sodium $\left(50 \mathrm{mg} \cdot \mathrm{kg}^{-1}\right.$, intraperitoneal) and exsanguinated. Thoracic aortas were removed, cleaned of fat and connective tissue, and cut into ring segments (4-5 mm in length). In some preparations, the endothelium was damaged by gently abrading the intimae of aortic rings with the tip of small forceps. The isolated arteries were placed in $10 \mathrm{ml}$ tissue chambers filled with Krebs-bicarbonate solution (KBS) of the following composition (mM): $\mathrm{NaCl} 118, \mathrm{KCl} 4.7, \mathrm{KH}_{2} \mathrm{PO}_{4}$ 1.2, $\mathrm{MgSO}_{4} 1.2, \mathrm{CaCl}_{2} 2.5, \mathrm{NaHCO}_{3} 25$, and dextrose 11.7. High $\mathrm{K}^{+}$ (40 and $80 \mathrm{mM}$ ) depolarizing solutions were prepared with equimolar replacement of $\mathrm{NaCl}$ with $\mathrm{KCl}$. The medium was gassed continuously $\left(95 \% \mathrm{O}_{2}, 5 \% \mathrm{CO}_{2}\right)$ and maintained at $\mathrm{pH} 7.4^{\circ} \mathrm{C}$ and $37^{\circ} \mathrm{C}$. Each tissue sample was placed under an initial resting tension of a $2 \mathrm{~g}$ mass and equilibrated for $60 \mathrm{~min}$ prior to the execution of the experimental protocols. Contractions were measured isometrically and recorded on a computer with the AcqKnowledge software (MP100WSW; Biopac Systems, Inc., Santa Barbara, CA, USA). Functional endothelium was determined by the presence of at least $80 \%$ relaxation in response to acetylcholine $(1 \mu \mathrm{M})$ after pre-constricting the tissues with PHE $(1 \mu \mathrm{M})$. Otherwise, successful endothelial denudation was confirmed by the presence of small (less than 10\%) relaxations, or absence of relaxations, in response to acetylcholine.

\section{Acute in vitro T3 treatment}

Cumulative concentration-response curves (CRCs) for T3 in aortic tissues pre-contracted with $\mathrm{PHE}$

Aortic rings with endothelium received PHE $(1 \mu \mathrm{M})$ and contractions were let to stabilize for $15 \mathrm{~min}$. Next, increasing concentrations of T3 $(1 \mathrm{nM}-10 \mu \mathrm{M})$ were added to the tissues, every 30 min; temporal controls received the corresponding concentration of the vehicle.

CRCs to relaxant and contractile agonists in in vitro T3treated aortic tissues

After the stabilization period, T3 $(0.01,01$, and $1 \mu \mathrm{M})$ or vehicle (vehicle concentration needed to dissolve T3 $1 \mu \mathrm{M}$ ) was administered to endothelium-intact aortic rings for 30 or $120 \mathrm{~min}$. Then, aortic rings were stimulated with PHE $(1 \mu \mathrm{M})$, contractions were stabilized (15 min) and CRCs to acetylcholine (endotheliumdependent relaxing agonist) or sodium nitroprusside (SNP; endothelium-independent relaxing drug, a NO donor) were generated.

In other series of experiments, aortic rings with endothelium were independently treated with T3 or vehicle as explained before; subsequently, CRCs to PHE (selective $\alpha_{1}$-adrenergic receptors agonist) or angiotensin II (ANG II; non-selective agonist of ANG II type 1 and type 2 receptors) were developed.

\section{Short-term in vivo T3 treatment}

CRCs to relaxant agonists in aortic tissues from short-term in vivo $\mathrm{T} 3$-treated rats

In $\mathrm{T}_{1 \mathrm{~d}}$ and $\mathrm{V}_{1 \mathrm{~d}}$ rats, CRCs to acetylcholine and SNP were obtained in endothelium-intact aortic rings pre-contracted with PHE $(1 \mu \mathrm{M})$. Since the contractions induced by PHE were significantly diminished in aortic rings of $\mathrm{T}_{3 \mathrm{~d}}$ rats (see Results), the CRCs to acetylcholine and SNP were tested at the same level of pre-contraction obtained by appropriately selected concentrations of PHE in endothelium-intact aortic tissues from $\mathrm{T}_{3 \mathrm{~d}}$ and $\mathrm{V}_{3 \mathrm{~d}}$ rats.

Contractile stimuli in aortic tissues of short-term in vivo T3treated rats

In annular segments with endothelium of thoracic aortas from $T 3_{1 \mathrm{~d}}, T 3_{3 \mathrm{~d}}, \mathrm{~V}_{1 \mathrm{~d}}$, and $\mathrm{V}_{3 \mathrm{~d}}$ rats, CRCs to PHE were built. Since the CRCs to PHE were inhibited in endothelium-intact aortic rings of $\mathrm{T}_{3 \mathrm{~d}}$ rats compared to their respective temporal controls (see Results), to inquire about the endothelium participation in this T3-elicited vasodepressor effect, PHE-induced CRCs were developed in endothelium-denuded aortic rings of $\mathrm{T}_{3 \mathrm{~d}}$ and $\mathrm{V}_{3 \mathrm{~d}}$ rats. Furthermore, CRCs to PHE were constructed in aortic rings with endothelium of $\mathrm{T}_{3 \mathrm{~d}}$ and $\mathrm{V}_{3 \mathrm{~d}}$ rats, 30 min after their incubation with the inhibitor of NOS, $\mathrm{N}^{\mathrm{G}}$-nitro-L-arginine methyl ester (LNAME, $100 \mu \mathrm{M})$. These studies indicated that the observed effect of $\mathrm{T}_{3 \mathrm{~d}}$-treatment on PHE-induced contractions in aortic rings was endothelium-independent (see Results and Discussion); thus, the following experiments with ANG II and high $\mathrm{K}^{+}$were developed in endothelium-denuded aortic tissues.

In endothelium-denuded aortic rings from $\mathrm{T}_{3 \mathrm{~d}}$ and $\mathrm{V}_{3 \mathrm{~d}}$ rats, CRCs to ANG II were constructed. Besides, high $\mathrm{K}^{+}$depolarizing solutions were used to circumvent $G$ protein-coupled receptors (GPCR). Endothelium-denuded aortic rings of $\mathrm{T}_{3 \mathrm{~d}}$ and $\mathrm{V}_{3 \mathrm{~d}}$ rats were constricted with high $\mathrm{K}^{+}(40$ and $80 \mathrm{mM})$ solutions, and contractions were stabilized for $30 \mathrm{~min}$.

For all purposes, each aortic ring was subjected to only one of the described procedures.

\section{Chemicals}

3,5,3' triiodo-L-tironine, L-phenylephrine hydrochloride, acetylcholine chloride, sodium nitroprusside, angiotensin II, LNAME (Sigma Chemical Company, St. Louis, MO, USA). T3 was dissolved as already explained. The other drugs were dissolved in distilled water, and subsequent dilutions were made using assay buffer.

\section{Statistical analysis}

Results are reported as means \pm standard error of the means for the number of rats or samples (number) obtained from 4-8 different rats. Comparisons between two independent groups 
were made using an unpaired Student t-test, and between multiple groups using one-way analysis of variance (ANOVA). Twoway ANOVA was used to compare two or more CRCs. Where one-way or two-way ANOVA showed significant differences, the results were analyzed further using the Tukey or Sidak post-hoc test, respectively (Prism version 6.0; Graph Pad Software, San Diego, CA, USA). In all comparisons, a value of $\mathrm{p}<0.05$ was considered statistically significant.

\section{RESULTS}

\section{PHE-induced pre-contractions in aortic tissues are not altered by $\mathrm{T} 3$ in vitro application}

In endothelium-intact aortic rings contracted with PHE (1 $\mu \mathrm{M})$, increasing cumulative concentrations of T3 $(1 \mathrm{nM}-10 \mu \mathrm{M})$ did not cause modifications of contractile tone compared to temporal controls (Fig. 1).

\section{Relaxant and contractile responses to selective agonists in aortic tissues stayed unchanged by in vitro T3-treatments}

Acetylcholine and SNP in a concentration-dependent manner produced relaxations of endothelium-intact aortic rings contracted with PHE. In vitro treatment with T3 $(0.01,0.1$, and $1 \mu \mathrm{M})$ for $30 \mathrm{~min}$ or $2 \mathrm{~h}$ did not alter the CRCs to either acetylcholine or SNP compared to their respective controls receiving vehicle (Fig. 2).

Compared to temporal controls, CRCs elicited by either PHE

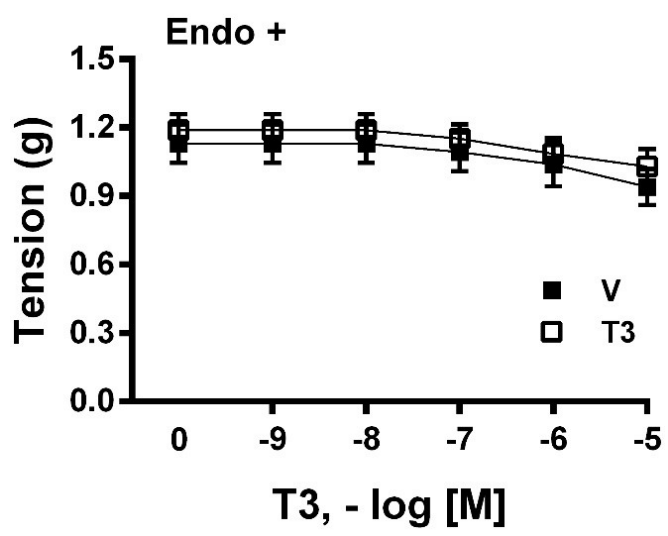

Fig. 1. Triiodothyronine (T3) applied in vitro did not influence previously established aortic active tonus. Cumulative administration of increasing concentrations of T3, every $30 \mathrm{~min}$, in endothelium intact $($ Endo + ) aortic rings contracted with phenylephrine $(1 \mu \mathrm{M})$. Temporal controls received the corresponding concentration of vehicle $(\mathrm{V})$. Values are presented as means \pm standard error of the means $(n=16) . p=$ not significant (two-way ANOVA).
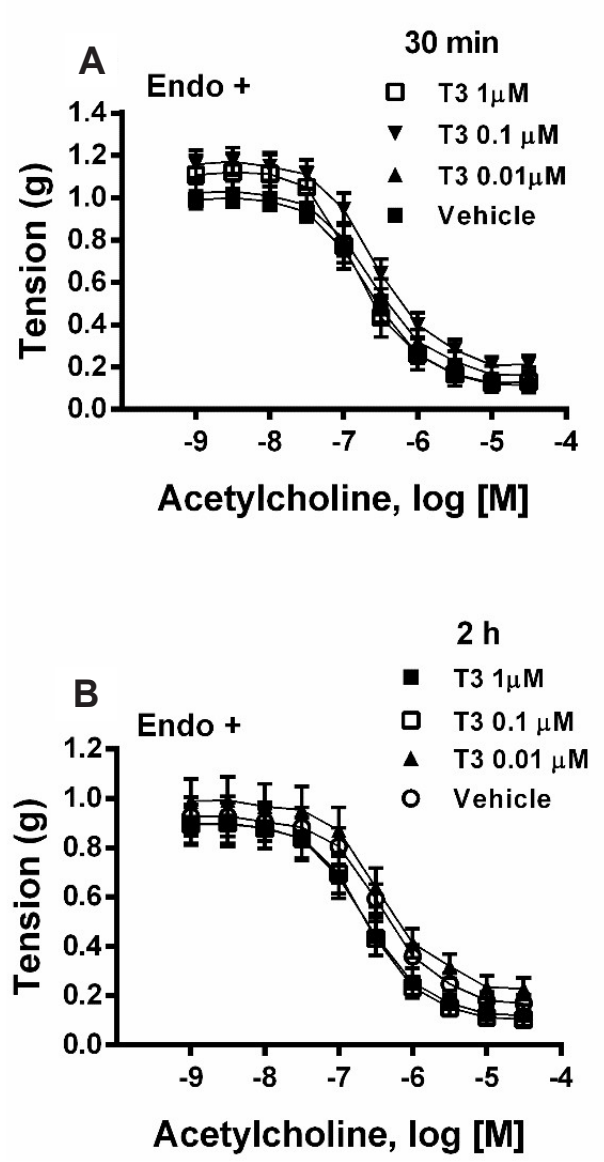

Korean J Physiol Pharmacol 2020;24(4):339-348

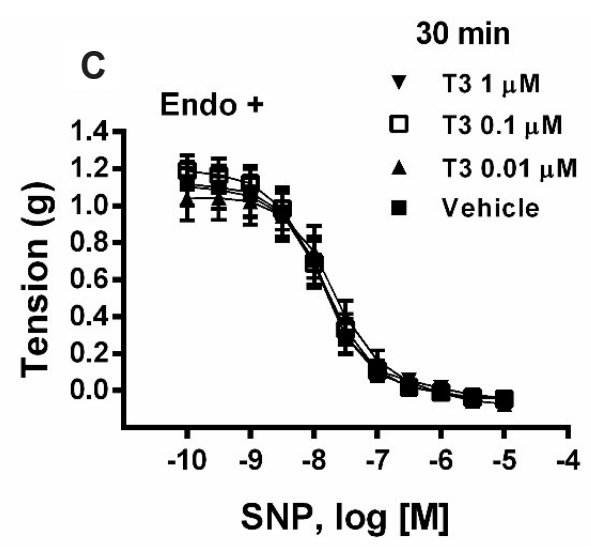

2 h

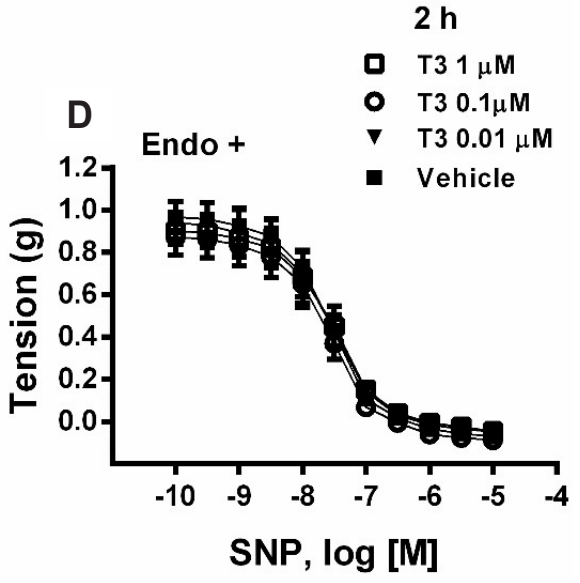
thyronine (T3) in vitro treatments on the relaxing responses of agonists in aortic tissues. (A, B) Relaxing responses to acetylcholine and $(C, D)$ sodium nitroprusside (SNP) in endothelium-intact aortic rings (Endo + ) contracted with phenylephrine $(1 \mu \mathrm{M})$, treated previously with $\mathrm{T} 3(0.01,0.1$, and $1 \mu \mathrm{M})$ or vehicle (V) during $30 \mathrm{~min}$ or $2 \mathrm{~h}$. Vehicle concentration corresponds to that required to dissolve T3 $1 \mu \mathrm{M}$. Relaxing responses were calculated as decreases of phenylephrine-induced tension (grams). Values are presented as means \pm standard error of the means ( $n=15-16) \cdot p=$ not significant (two-way ANOVA). 
or ANG II in aortic rings with endothelium were not modified in the presence of $\mathrm{T} 3(0.01,0.1$, and $1 \mu \mathrm{M})$ administered beforehand during $30 \mathrm{~min}$ or $2 \mathrm{~h}$ (Fig. 3).

\section{Short-term in vivo T3-treatment efficiently induced hyperthyroidism in rats}

Serum fT3 was increased and TSH decreased, both significantly, in $\mathrm{T}_{1 \mathrm{~d}}$ and $\mathrm{T} 3_{3 \mathrm{~d}}$ compared respectively with $\mathrm{V}_{1 \mathrm{~d}}$ and $\mathrm{V}_{3 \mathrm{~d}}$ rats (Table 1). These data indicate the hyperthyroid state of T3-treated rats. Serum concentrations of $\mathrm{fT} 3$ augmented in $\mathrm{T} 3_{3 \mathrm{~d}}$ concerning $\mathrm{T} 3_{1 \mathrm{~d}}$ rats (Table 1). Thus, a rise in intensity of the hyperthyroid state on $\mathrm{T}_{3 \mathrm{~d}}$ rats is appreciated. However, TSH concentrations did not vary in a significant way between $\mathrm{T} 3_{1 \mathrm{~d}}$ and $\mathrm{T} 3_{3 \mathrm{~d}}$ rats (Table 1 ). The body mass of $\mathrm{T}_{3 \mathrm{~d}}$ rats was significantly lesser than that of $\mathrm{V}_{3 \mathrm{~d}}$ rats (Table 1). $\mathrm{T} 3_{1 \mathrm{~d}}$ rats did not alter their body mass compared to $\mathrm{V}_{1 \mathrm{~d}}$ rats. The stimulatory effects of THs on metabolic activity can explain the loss of body mass [18]. Contrasted with their respec- tive time-based controls, $\mathrm{T} 3_{3 \mathrm{~d}}$ - but not $\mathrm{T} 3_{1 \mathrm{~d}}$-treatment led to cardiac hypertrophy determined by an increase in heart dry mass to tibia length ratio (Table 1). Overall, these findings confirm the hyperthyroid status of animals submitted to treatment with T3 $[1,3,18]$.

\section{Relaxant responses to selective agonists remained unaltered in aortic tissues of short-term in vivo T3- treated rats}

Acetylcholine caused concentration-dependent relaxant responses in endothelium-intact aortic rings from $\mathrm{T}_{1 \mathrm{~d}}$ and $\mathrm{V}_{1 \mathrm{~d}}$ rats, or $\mathrm{T}_{3 \mathrm{~d}}$ and $\mathrm{V}_{3 \mathrm{~d}}$ rats, which did not differ between them, respectively (Fig. 4). Likewise, the concentration-dependent relaxations induced by SNP in aortic rings with endothelium of $\mathrm{T}_{1 \mathrm{~d}}$ and $\mathrm{V}_{1 \mathrm{~d}}$ rats, or $\mathrm{T}_{3 \mathrm{~d}}$ and $\mathrm{V}_{3 \mathrm{~d}}$ rats, were in that order analogous (Fig. 4). When compared, the CRCs to acetylcholine and SNP were initiated under isotonic pre-contractions (Fig. 4).
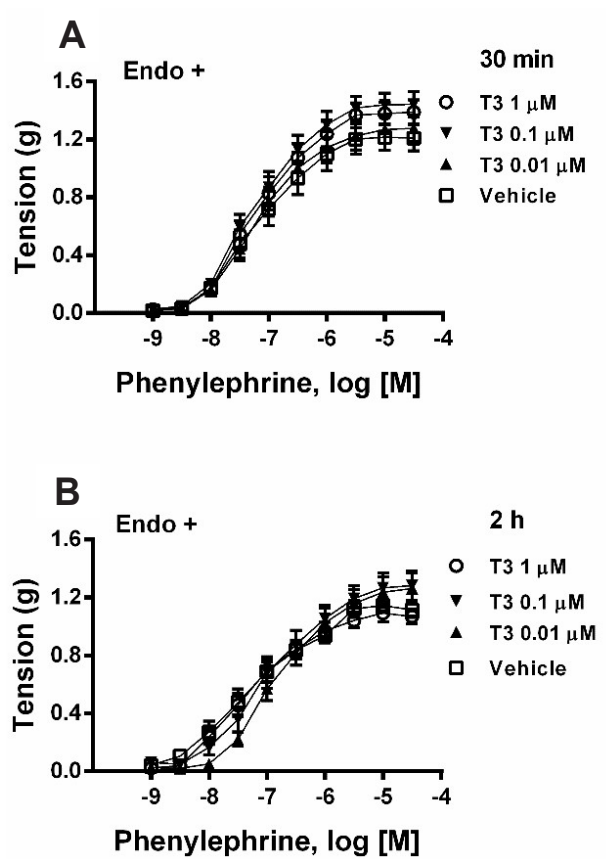
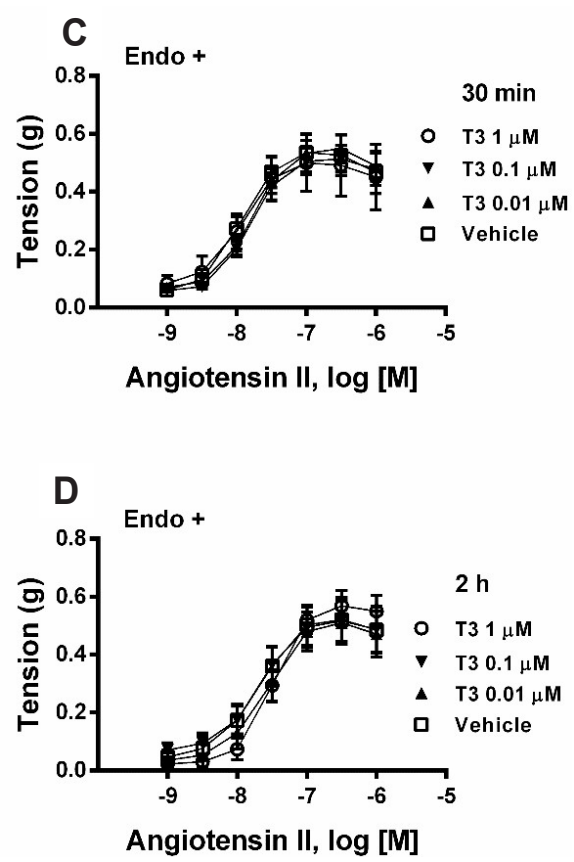

Fig. 3. Lack of effect of in vitro 3,5,3' triiodo-L-thyronine (T3) treatments on the contractile responses to agonists in aortic segments. (A, B) Cumulative concentration-response curves to Phenylephrine and (C, D) Angiotensin II in annular segments of aortas with endothelium (Endo + ) treated previously with $\mathrm{T} 3(0.01,0.1$, and $1 \mu \mathrm{M})$ or vehicle $(\mathrm{V})$ for $30 \mathrm{~min}$ and $2 \mathrm{~h}$. Vehicle concentration corresponded to that required to dissolve T3 $1 \mu \mathrm{M}$. The contractile responses represent grams of developed tension. Values are presented as means \pm standard error of the means $(n=16) . p=$ not significant (two-way ANOVA).

Table 1. Validation of short-term hyperthyroidism

\begin{tabular}{clllc}
\hline Treatment & fT3 $(\mathrm{pg} / \mathrm{ml})$ & TSH $(\mathrm{ng} / \mathrm{ml})$ & BM $(\mathrm{g})$ & LVdM/LT $(\mathrm{mg} / \mathrm{mm})$ \\
\hline $\mathrm{V}_{1 \mathrm{~d}}$ & $2.54 \pm 0.18$ & $1.79 \pm 0.18$ & $286.82 \pm 3.52$ & $4.16 \pm 0.24$ \\
$\mathrm{~T}_{1 \mathrm{~d}}$ & $6.38 \pm 0.49^{\mathrm{a}}$ & $0.28 \pm 0.07^{\mathrm{a}}$ & $282.74 \pm 3.57$ & $4.69 \pm 0.33$ \\
$\mathrm{~V}_{3 \mathrm{~d}}$ & $2.11 \pm 0.27$ & $1.83 \pm 0.11$ & $292.45 \pm 3.75$ & $4.33 \pm 0.30$ \\
$\mathrm{~T}_{3 \mathrm{~d}}$ & $9.91 \pm 0.72^{\mathrm{b}, \mathrm{c}}$ & $0.18 \pm 0.02^{\mathrm{b}}$ & $275.56 \pm 3.60^{\mathrm{d}}$ & $5.66 \pm 0.25^{\mathrm{e}}$ \\
\hline
\end{tabular}

Values are presented as means \pm standard error of the means. Serum levels of free 3,5,3' triiodo-L-thyronine (fT3) and thyroid stimulating hormone (TSH). Body mass (BM) values. Left ventricular dry mass to tibia length (LVdM/TL) ratio as an indicator of cardiac hypertrophy. Short-term hyperthyroidism in rats was induced by daily subcutaneous injection of T3 $\left(500 \mu g^{\circ} \mathrm{kg}^{-1}\right)$ for $1\left(\mathrm{~T}_{1 \mathrm{~d}}\right)$ and $3\left(\mathrm{~T}_{3 \mathrm{~d}}\right)$ days. Control animals were injected every day with the vehicle $\left(1 \mathrm{ml} \cdot \mathrm{kg}^{-1} \cdot \mathrm{d}^{-1}\right)$ for $1\left(\mathrm{~V}_{1 \mathrm{~d}}\right)$ and $3\left(\mathrm{~V}_{3 \mathrm{~d}}\right)$ days. ${ }^{\mathrm{a}} \mathrm{p}<0.05 \mathrm{vs}$. $\mathrm{V}_{1 \mathrm{~d} d} \mathrm{~b}^{\mathrm{b}} \mathrm{p}<0.05 \mathrm{vs}$. $\mathrm{V}_{3 \mathrm{~d},}{ }^{\mathrm{c}} \mathrm{p}<0.05$ vs. $\mathrm{T} 3_{1 \mathrm{~d},} \mathrm{n}=6$ rats per group (one-way ANOVA with Tukey post-hoc test). ${ }^{\mathrm{d}} \mathrm{p}<0.05$ vs. $\mathrm{V}_{3 \mathrm{~d}}, \mathrm{n}=30$ rats per group (unpaired Student t-test). ${ }^{\mathrm{e}} \mathrm{p}<0.05$ vs. $\mathrm{V}_{3 \mathrm{~d}} ; \mathrm{n}=8$ hearts per group (one-way ANOVA with Tukey post-hoc test). 

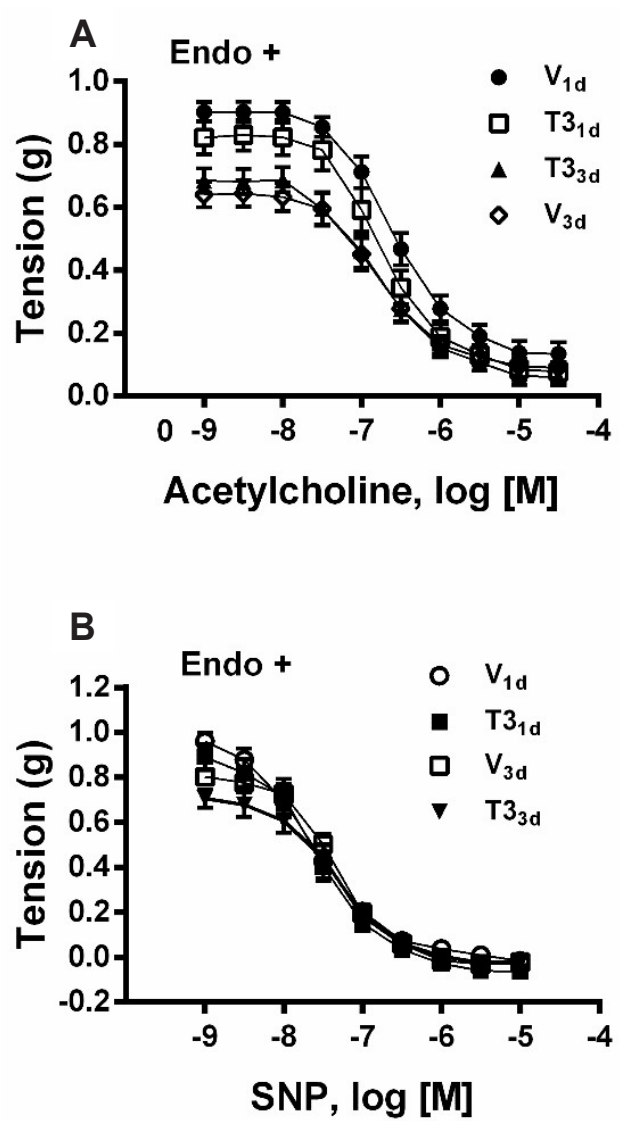

Fig. 4. Short-term in vivo 3,5,3' triiodo-L-thyronine (T3) treatment did not affect relaxant responses of agonists in aortic tissues. (A) Cumulative concentration-relaxing response curves to acetylcholine and (B) sodium nitroprusside (SNP) in endothelium-intact (Endo +) thoracic aortic rings isolated from rats treated subcutaneously with $\mathrm{T3}$ (500 $\left.\mu \mathrm{g} \cdot \mathrm{kg}^{-1} \cdot \mathrm{d}^{-1}\right)$ or vehicle $\left(\mathrm{V} ; 1 \mathrm{ml} \cdot \mathrm{kg}^{-1} \cdot \mathrm{d}^{-1}\right)$ for 1 and 3 days $\left(\mathrm{T}_{1 \mathrm{~d}}, \mathrm{~T} 3_{3 \mathrm{~d}}\right.$ and $\mathrm{V}_{1 \mathrm{~d}}, \mathrm{~V}_{3 \mathrm{~d}}$, respectively). Relaxing responses were calculated as decreases of phenylephrine-induced tension. Values are presented as means \pm standard error of the means $(n=14-16) . p=$ not significant (two-way ANOVA).

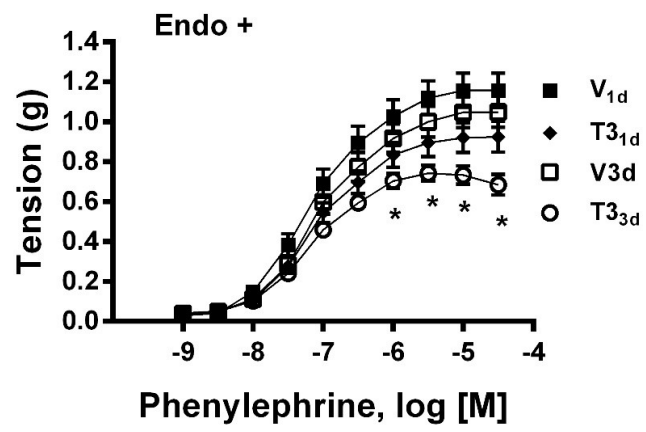

Fig. 5. Delayed depression of Phenylephrine-induced contractions in aortic tissues from short-term thyroid hormone-treated rats. Cumulative concentration-contractile response curves to phenylephrine, in endothelium-intact (Endo + ) thoracic aortic rings isolated from rats treated subcutaneously with 3,5,3' triiodo-L-thyronine (T3; 500 $\left.\mu \mathrm{g} \cdot \mathrm{kg}^{-1} \cdot \mathrm{d}^{-1}\right)$ or vehicle $\left(\mathrm{V} ; 1 \mathrm{ml} \cdot \mathrm{kg}^{-1} \cdot \mathrm{d}^{-1}\right)$ for 1 and 3 days $\left(\mathrm{T}_{1 \mathrm{~d}}, \mathrm{~T} 3_{3 \mathrm{~d}}\right.$ and $V_{1 d}, V_{3 d}$, respectively). Contractile responses are expressed as grams (g) of developed force. Values are presented as means \pm SEM $(n=16)$. ${ }^{*} p<$ $0.05 \mathrm{T3}_{3 \mathrm{~d}}$ vs. $\mathrm{V}_{3 \mathrm{~d}}$ (two-way ANOVA with Sidak's post-hoc test).
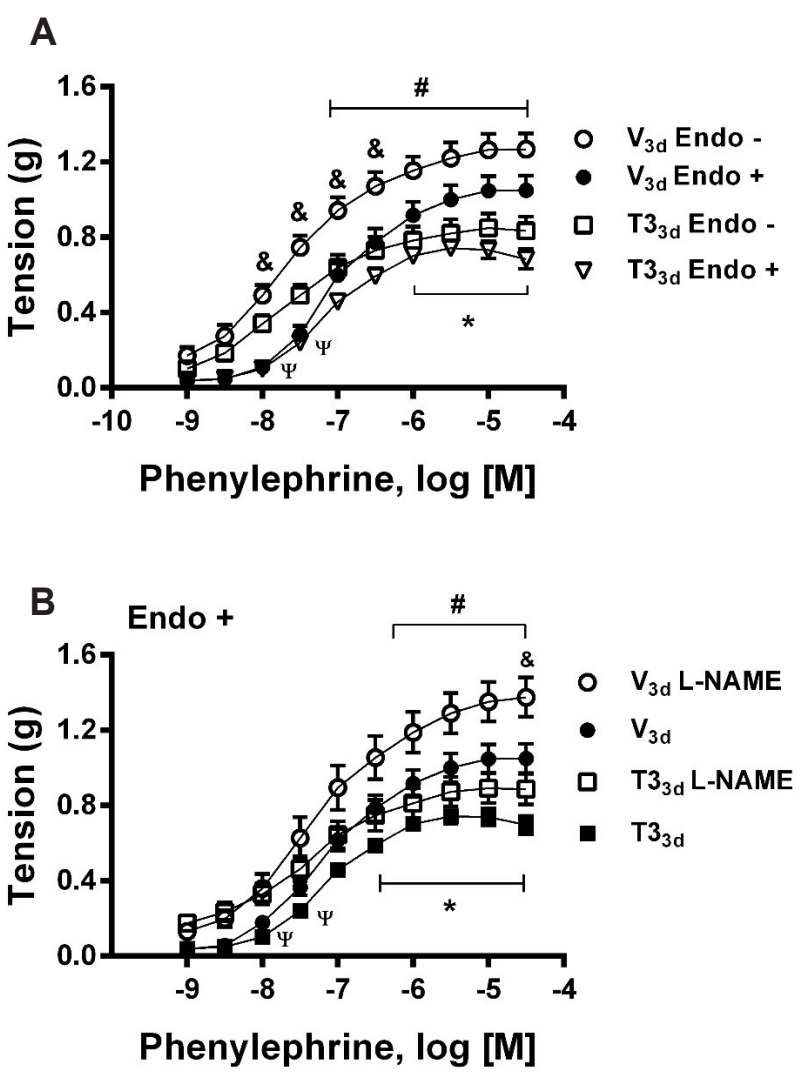

Fig. 6. Endothelium-independent inhibition of contractile responses to Phenylephrine in aortic tissues from 3,5,3' triiodo-L-thyronine (T3) in vivo treated rats. (A) Cumulative concentration-response curves (CRCs) to phenylephrine in annular segments of aortas with (Endo + ) and without (Endo -) endothelium. (B) CRCs to phenylephrine in endothelium-intact (Endo + ) thoracic aortic rings in the presence or absence of $\mathrm{N}^{G}$-Nitro-L-arginine methyl ester (L-NAME, $\left.100 \mu \mathrm{M}\right)$. Aortic tissues were obtained from rats treated with subcutaneous injections of T3 $\left(500 \mu \mathrm{g} \cdot \mathrm{kg}^{-1} \cdot \mathrm{d}^{-1}\right)$ or vehicle $\left(1 \mathrm{ml} \cdot \mathrm{kg}^{-1} \cdot \mathrm{d}^{-1}\right)$ for 3 days $\left(\mathrm{T}_{3 \mathrm{~d}}\right.$ and $\mathrm{V}_{3 \mathrm{~d}}$, respectively). All data are expressed as grams $(\mathrm{g})$ of developed force. Values are presented as means \pm standard error of the means. (A) $(n=$ 16) ${ }^{*} \mathrm{p}<0.05 \mathrm{T3}_{3 \mathrm{~d}}\left(\right.$ Endo + ) vs. $\mathrm{V}_{3 \mathrm{~d}}\left(\right.$ Endo + ); ${ }^{*} \mathrm{p}<0.05 \mathrm{T3}_{3 \mathrm{~d}}$ (Endo - ) vs. $\mathrm{V}_{3 \mathrm{~d}}$ (Endo -); ${ }^{\psi} \mathrm{p}<0.05 \mathrm{T3}_{3 \mathrm{~d}}$ (Endo +) vs. T3 $3_{3 \mathrm{~d}}$ (Endo -); ${ }^{*} \mathrm{p}<0.05 \mathrm{~V}_{3 \mathrm{~d}}$ (Endo + ) vs. $\mathrm{V}_{3 \mathrm{~d}}($ Endo -$)$. Two-way ANOVA with Sidak's post-hoc test. (B) $(\mathrm{n}=14-16)$ ${ }^{*} \mathrm{p}<0.05 \mathrm{T3}_{3 \mathrm{~d}}$ Vs. V $\mathrm{V}_{3 \mathrm{~d}}$; ${ }^{*} \mathrm{p}<0.05 \mathrm{T3}_{3 \mathrm{~d}}$ L-NAME vs. V $\mathrm{V}_{3 \mathrm{~d}}$ L-NAME; ${ }^{*} \mathrm{p}<0.05$ $\mathrm{T3}_{3 \mathrm{~d}}$ vs. $\mathrm{T3}_{3 \mathrm{~d}}$ L-NAME; ${ }^{\mathrm{P}} \mathrm{p}<0.05 \mathrm{~V}_{3 \mathrm{~d}}$ vs. $\mathrm{V}_{3 \mathrm{~d}}$ L-NAME. Two-way ANOVA with Sidak's post-hoc test.

\section{Depression of contractile responses to PHE, ANG II, and high $\mathrm{K}^{+}$in aortic tissues from short-term in vivo T3-treated rats}

When associated, endothelium-intact aortic rings of $T 3_{1 d}, V_{1 d}$, and $\mathrm{V}_{3 \mathrm{~d}}$ rats showed not statistically different CRCs to PHE (Fig. 5); nevertheless, the CRCs to PHE of $\mathrm{T}_{1 \mathrm{~d}}$ rats displayed a tendency toward a reduced maximal response (20\%). PHE-induced CRCs in aortic segments with endothelium of $\mathrm{T}_{3 \mathrm{~d}}$ rats were significantly depressed (35\%) in comparison to their respective $\mathrm{V}_{3 \mathrm{~d}}$ controls (Figs. 5 and 6A). Furthermore, in vivo T3-treatment for 3 days, 
decreased the CRCs to PHE (34\%) in endothelium-denuded aortic rings compared to their corresponding $\mathrm{V}_{3 \mathrm{~d}}$ controls (Fig. 6A). Equally, CRCs to PHE were observed statistically depressed (36\%) in endothelium-intact, L-NAME-treated, aortas of $\mathrm{T}_{3 \mathrm{~d}}$ rats (Fig. 6B).

Once the CRCs for PHE in aortic rings with and without endothelium from either $\mathrm{T}_{3 \mathrm{~d}}$ or $\mathrm{V}_{3 \mathrm{~d}}$ rats were respectively compared (Fig. 6A), the contractile activity in aortic rings without endothelium was detected higher than in tissues with endothelium in the two groups of rats. However, the contractile responses to PHE in endothelium-denuded aortas continued largely depressed (34\%) in $\mathrm{T}_{3 \mathrm{~d}}$ compared to $\mathrm{V}_{3 \mathrm{~d}}$ rats (Fig. $6 \mathrm{~A}$ ). In the same way, treatment with L-NAME significantly increased the contractions caused by PHE in endothelium-intact aortic tissues of $\mathrm{T}_{3 \mathrm{~d}}$ and $\mathrm{V}_{3 \mathrm{~d}}$ rats (Fig. 6B); nevertheless, in the L-NAME presence, the CRCs to PHE in aortic rings from $\mathrm{T}_{3 \mathrm{~d}}$ compared to $\mathrm{V}_{3 \mathrm{~d}}$ rats, remained clearly inhibited (36\%) (Fig. 6B). In this way, the data indicate that the endothelium and, particularly, NO seem not to participate in the depression of contractile responses to PHE in aortic rings of $\mathrm{T}_{3 \mathrm{~d}}$ rats (see Discussion).

To investigate the selectivity of the depression of contractile responses to PHE in aortic rings from $\mathrm{T}_{3 \mathrm{~d}}$ rats, experiments were carried out with ANG II (acting on a different family of receptors) and high $\mathrm{K}^{+}$depolarizing solutions (as a receptor-independent stimulus). In endothelium-denuded aortic rings, the CRCs to ANG II were significantly diminished (40\%) after $\mathrm{T}_{3 \mathrm{~d}}$-treatment concerning time-matched control tissues (Fig. 7A). Additionally, high $\mathrm{K}^{+}(40$ and $80 \mathrm{mM}$ ) contractile responses in endotheliumdenuded aortic preparations of $\mathrm{T}_{3 \mathrm{~d}}$ rats, were inhibited (35\% and $32 \%$, respectively) when compared with the corresponding responses in $\mathrm{V}_{3 \mathrm{~d}}$ tissues (Fig. 7B).

\section{DISCUSSION}

Taken together, the data indicate that $\mathrm{T} 3$, administered in vitro, neither modified the active tone previously established by PHE nor the effects of both relaxant and contractile agonists in rat thoracic aortas with endothelium. However, short-term in vivo T3 administration significantly reduced contractile tone development in isolated thoracic aortas, with a latency greater than one day. $\mathrm{T}_{3 \mathrm{~d}}$-treatment equally decreased the CRCs to PHE in endothelium-intact, endothelium-denuded, and endothelium-intact NOS inhibitor-treated, aortic rings. Moreover, $\mathrm{T}_{3 \mathrm{~d}}$ treatment depressed the contractile responses of ANG II and high $\mathrm{K}^{+}$independently of the endothelial function and, in contrast, the agonistinduced endothelium-dependent and -independent relaxations were not modified in rat aortas. Hence, short-term thyrotoxicosis induced by $\mathrm{T} 3$ in rats lessened the ability of the aortic smooth muscle to contract, but not to relax, in an endothelium- and NOindependent way. The temporal course of occurrence of this depressant effect suggests that it is mediated by genomic or through non-genomic/genomic mechanisms. Otherwise, T3 does not
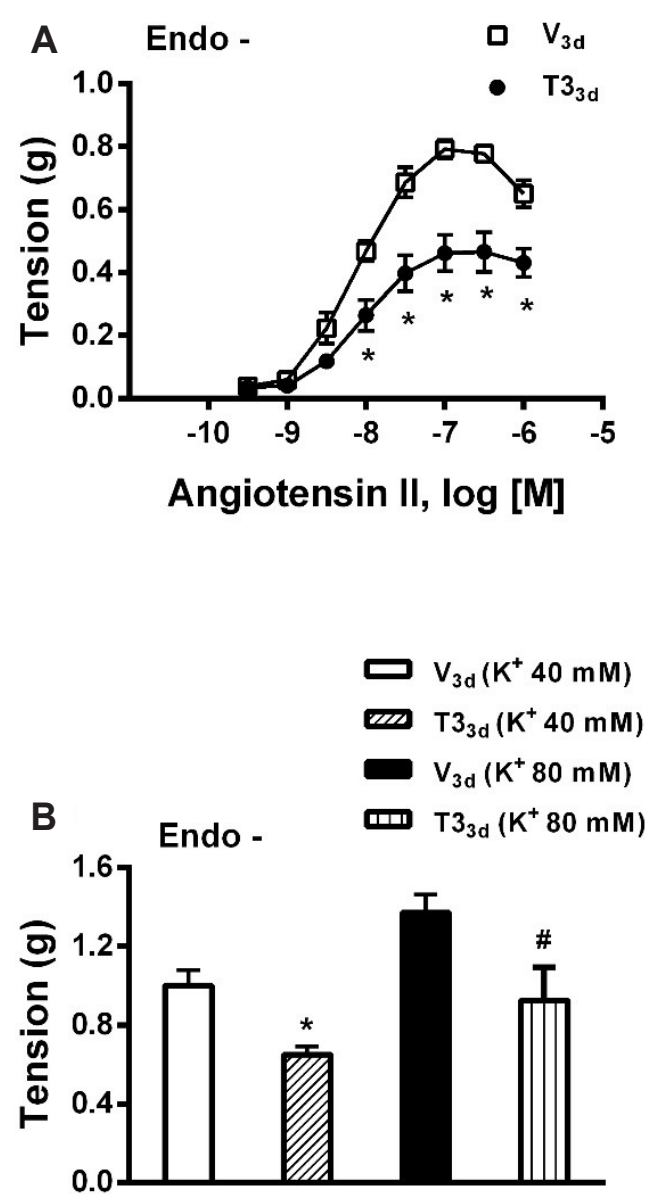

Fig. 7. Endothelium-independent inhibition of contractile responses to angiotensin II and high $\mathrm{K}^{+}$in aortic tissues from thyroid hormone-treated rats. (A) Cumulative concentration-response curves to angiotensin II in endothelium-denuded (Endo -) thoracic aortic rings. (B) Contractile responses to high $\mathrm{K}^{+}(40$ and $80 \mathrm{mM}$ ) in endothelium-denuded (Endo -) thoracic aortic rings. Aortic tissues were obtained from rats treated with subcutaneous injections of 3,5,3' triiodoL-thyronine $\left(500 \mu \mathrm{g} \cdot \mathrm{kg}^{-1} \cdot \mathrm{d}^{-1}\right)$ or vehicle $\left(1 \mathrm{ml} \cdot \mathrm{kg}^{-1} \cdot \mathrm{d}^{-1}\right)$ for 3 days $\left(\mathrm{T}_{3 \mathrm{~d}}\right.$ and $V_{3 d}$, respectively). All data are expressed as grams ( $\mathrm{g}$ ) of developed force. Values are presented as means \pm standard error of the means. (A) $(\mathrm{n}=15){ }^{*} \mathrm{p}<0.05$ vs. $\mathrm{V}_{3 \mathrm{~d}}$ (two-way ANOVA with Sidak's post-hoc test). (B) $(n=13-15) * p<0.05$ vs. $V_{3 d}\left(K^{+} 40 \mathrm{mM}\right) ;{ }^{\#} p<0.05$ vs. $V_{3 d}\left(K^{+} 80 \mathrm{mM}\right)$ (unpaired Student t-test).

modify aortic contractility by a rapid non-genomic mechanism, as shown by its lack of effect when applied acutely in vitro.

Influences of acute in vitro and short-term in vivo T3 treatments on the responses of isolated rat thoracic aortas to contractile and relaxant stimuli were studied comparatively. A fundamental consideration was that there have been described in small and large blood vessels, rapid (seconds to minutes) non-genomic effects of THs contrasting with their genomic or non-genomic/ genomic effects of delayed presentation (from several hours on) [5]. The latest effects are initiated in TR located in the plasma membrane or cytoplasm, eventually, associated with gene transcription $[5,6]$. Admittedly, some studies have reported a direct vasodepres- 
sor action of THs that may be interpreted as rapid non-genomic. Park et al. [9] showed that T3 and T4 cause rapid onset vasodilator responses $(20 \mathrm{~min}$ ) acting on both the endothelium and smooth muscle of isolated skeletal muscle resistance arteries of rats. Besides, Carrillo-Sepúlveda and colleagues [10] reported that in 30 min, T3 inhibited contractile responses to PHE in endotheliumdenuded rat thoracic aortas by inducing smooth muscle synthesis of NO. In endothelium-intact rat thoracic aortas, however, we found that increasing cumulative concentrations of T3 (every 30 minutes up to 2 and a half hours) did not provoke alterations in contractile tone induced by PHE, as would be expected if T3 were inducing NO-dependent relaxation by a rapid non-genomic action in endothelial or smooth muscle cells. Additionally, in vitro $\mathrm{T} 3$ treatment with concentrations $(0.01,0.1$, and $1 \mu \mathrm{M}$ for $30 \mathrm{~min}$ or two hours) that include those reported as inducing vasodepressor effects by a rapid non-genomic mechanism $[9,10]$ did not modify the relaxant responses produced by acetylcholine (whose vasodepressor effect depends on endothelium-derived $\mathrm{NO}$ ) and SNP (which breaks down releasing NO) in endothelium-intact aortic rings contracted with PHE. In this way, synthesis and release of endothelial NO induced by agonist or the relaxant action of NO in the smooth muscle do not seem to be affected in aortas of rats treated acutely in vitro with T3. Moreover, contractions triggered by PHE and ANG II in aortic rings with endothelium remained unchanged in the presence of $\mathrm{T} 3(0.01,0.1$, and $1 \mu \mathrm{M})$ administered previously for $30 \mathrm{~min}$ and $2 \mathrm{~h}$. In rat aorta, basal or induced NO release plays a key role in the endothelium-dependent depression of responses caused by contractile agonists [1923]. Hence, the data showed that neither endothelium nor NO, particularly, depressed the contractile responses obtained with either PHE or ANG II in aortic rings treated acutely in vitro with $\mathrm{T} 3$, as would be expected if synthesis and release of NO had been increased in aortic walls.

On the other hand, it has been reported that endothelial NOdependent vasodilation elicited by acetylcholine is increased, and contractile responses induced by norepinephrine are depressed in an endothelium-dependent manner, in aortic tissues of hyperthyroid rats by short-term T4 administration $\left(500 \mu \mathrm{g} \cdot \mathrm{kg}^{-1} \cdot \mathrm{d}^{-1}\right.$, 3 days) [11] and long-term T3 treatment $\left(300 \mu \mathrm{g} \cdot \mathrm{kg}^{-1} \cdot 2 \mathrm{~d}^{-1}, 6-12\right.$ weeks) [12]. Thus, both relaxing and contractile responses of rat aorta have been found modified by an increased vasodepressor function of the endothelium, caused by THs actions considered genomic $[12,13]$. Herein, it is important to point out that these studies, like most works with isolated vessels from hyperthyroid animals [8], were defined by a unique period of treatment; that is, the temporal evolution of functional changes in vascular responsiveness was not characterized. In our study, in vivo treatment with T3 $\left(500 \mu \mathrm{g} \cdot \mathrm{kg}^{-1} \cdot \mathrm{d}^{-1}\right)$ for 3 days, but not for 1 day, significantly decreased the contractile responses induced by PHE in aortic rings with and without endothelium, correlated with their respective controls from vehicle-treated rats. The absence of endothelium and L-NAME treatment $(100 \mu \mathrm{M})$ in the presence of endothelium, respectively, enhanced the contractile responses to PHE in aortic rings of $\mathrm{T}_{3 \mathrm{~d}}$ and $\mathrm{V}_{3 \mathrm{~d}}$ rats. However, the contractile responses to PHE remained mostly depressed in the aortas without endothelium, and with endothelium treated with L-NAME, of $\mathrm{T}_{3 \mathrm{~d}}$ rats when compared properly to those obtained from $\mathrm{V}_{3 \mathrm{~d}}$ rats. If depression of contractile responses to PHE in aortic tissues of $\mathrm{T}_{3 \mathrm{~d}}$ rats were fundamentally endothelium-dependent and mediated by NO, endothelium denudation and inhibition of NO synthesis should result in a left shift (potentiation) of CRCs to PHE significantly greater in these tissues than in controls tissues; depression of contractile responses to PHE ought to be practically reverted to the values obtained in the rings without endothelium of control $V_{3 \mathrm{~d}}$ animals. As mentioned, this was not the case.

An additional important finding was that contractile responses to ANG II and high $\mathrm{K}^{+}$in endothelium-denuded thoracic aortas under $\mathrm{T}_{3 \mathrm{~d}}$-treatment were also attenuated. Accordingly, CRCs to PHE in endothelium-denuded aortic tissues of $\mathrm{T}_{3 \mathrm{~d}}$ rats were not selectively depressed since CRCs to ANG II and contractile responses to high $\mathrm{K}^{+}$(a GPCR-independent stimulus), were significantly inhibited compared to their suitable controls of $\mathrm{V}_{3 \mathrm{~d}}$ rats. It is well known that PHE and ANG II, acting on different GPCR, mainly use the Gq/11-phospholipase $\mathrm{C}$ signaling pathway to stimulate vascular smooth muscle contraction via the release of sarcoplasmic reticulum stored $\mathrm{Ca}^{2+}$, extracellular $\mathrm{Ca}^{2+}$ influx (through voltage-dependent, receptor-operated, and store-operated channels), and concomitant $\mathrm{Ca}^{2+}$ sensitization [24-28]. On the other hand, extracellular $\mathrm{Ca}^{2+}$ entry through voltage-dependent $\mathrm{Ca}^{2+}$ channels is considered the main cause of contractions induced by elevated $\mathrm{K}^{+}$in vascular smooth muscle [29]; nonetheless, high $\mathrm{K}^{+}$also causes $\mathrm{Ca}^{2+}$ sensitization [30]. So, given the complexity of the signal transduction pathways involved in contractile activity caused by PHE, ANG II, and high $\mathrm{K}^{+}$, it is necessary to develop additional research to solve what actions common (or not) to these stimuli allow explaining the seemingly non-selective depression of contractile activity.

Deepening on the analysis of effects of short-term in vivo T3 treatments in endothelium and smooth muscle of rat aortas, we studied comparatively relaxant effects of acetylcholine and SNP on PHE pre-contracted aortic rings. Because PHE-induced contractions were significantly suppressed in aortic tissues of $\mathrm{T}_{3 \mathrm{~d}}$ rats compared with their time-based controls, the relaxations of Ach and SNP were tested under isotonic conditions (obtained by fittingly selected concentrations of PHE). Results indicate that $\mathrm{T}_{1 \mathrm{~d}}$ and $\mathrm{T}_{3 \mathrm{~d}}$ treatments did not modify CRCs to acetylcholine and SNP in endothelium-intact thoracic aortas. Thus, data put forward that acetylcholine-induced endothelial NO release and smooth muscle sensitivity to NO released by SNP, were not modified in aortas of $\mathrm{T}_{1 \mathrm{~d}}$ and $\mathrm{T}_{3 \mathrm{~d}}$ rats compared to their corresponding temporal controls.

Absence of agreement of our data with other publications requires further investigation; nonetheless, distinct researchers, using diverse isolated blood vessels, have found that responses to 
either contractile or relaxant agonists can be reduced, unchanged or enhanced in hyperthyroid animals, without expounding convincing explanations for these inconsistencies [8].

In summary, acute in vitro $\mathrm{T} 3$ administration did not alter smooth muscle contractility in rat thoracic aortas; however, shortterm in vivo $\mathrm{T} 3$ administration depressed contractile activity independently of the endothelium, and NO either of endothelial or smooth muscle origin, in isolated thoracic aortas. The time course of onset of this depressant effect suggests that it is mediated by slow development genomic or non-genomic/genomic mechanisms and excludes the participation of rapid non-genomic mechanisms. It remains to elucidate the mechanism by which short-term in vivo treatment with thyroid hormone causes depression of contractile response in rat thoracic aorta.

\section{ACKNOWLEDGEMENTS}

This work was supported by Secretaría de Investigación y Posgrado del Instituto Politécnico Nacional (SIP-IPN); Comisión de Operación y Fomento de Actividades Académicas del IPN (COFAA); Consejo Nacional de Ciencia y Tecnología (CONACYT).

\section{CONFLICTS OF INTEREST}

The authors declare no conflicts of interest.

\section{REFERENCES}

1. Fazio S, Palmieri EA, Lombardi G, Biondi B. Effects of thyroid hormone on the cardiovascular system. Recent Prog Horm Res. 2004;59:31-50.

2. Danzi S, Klein I. Thyroid hormone and the cardiovascular system. Med Clin North Am. 2012;96:257-268.

3. Danzi S, Klein I. Thyroid disease and the cardiovascular system. Endocrinol Metab Clin North Am. 2014;43:517-528.

4. Cini G, Carpi A, Mechanick J, Cini L, Camici M, Galetta F, Giardino $\mathrm{R}$, Russo MA, Iervasi G. Thyroid hormones and the cardiovascular system: pathophysiology and interventions. Biomed Pharmacother. 2009;63:742-753.

5. Davis PJ, Leonard JL, Davis FB. Mechanisms of nongenomic actions of thyroid hormone. Front Neuroendocrinol. 2008;29:211-218.

6. Cheng SY, Leonard JL, Davis PJ. Molecular aspects of thyroid hormone actions. Endocr Rev. 2010;31:139-170.

7. Klein I, Ojamaa K. Thyroid hormone: targeting the vascular smooth muscle cell. Circ Res. 2001;88:260-261.

8. Vargas F, Moreno JM, Rodríguez-Gómez I, Wangensteen R, Osuna A, Alvarez-Guerra M, García-Estañ J. Vascular and renal function in experimental thyroid disorders. Eur J Endocrinol. 2006;154:197212.

9. Park KW, Dai HB, Ojamaa K, Lowenstein E, Klein I, Sellke FW. The direct vasomotor effect of thyroid hormones on rat skeletal muscle resistance arteries. Anesth Analg. 1997;85:734-738.

10. Carrillo-Sepúlveda MA, Ceravolo GS, Fortes ZB, Carvalho MH, Tostes RC, Laurindo FR, Webb RC, Barreto-Chaves ML. Thyroid hormone stimulates NO production via activation of the PI3K/Akt pathway in vascular myocytes. Cardiovasc Res. 2010;85:560-570.

11. Honda H, Iwata T, Mochizuki T, Kogo H. Changes in vascular reactivity induced by acute hyperthyroidism in isolated rat aortae. Gen Pharmacol. 2000;34:429-434.

12. McAllister RM, Grossenburg VD, Delp MD, Laughlin MH. Effects of hyperthyroidism on vascular contractile and relaxation responses. Am J Physiol. 1998;274:E946-E953.

13. McAllister RM, Albarracin I, Price EM, Smith TK, Turk JR, Wyatt KD. Thyroid status and nitric oxide in rat arterial vessels. J Endocrinol. 2005;185:111-119.

14. Delp MD, McAllister RM, Laughlin MH. Exercise training alters aortic vascular reactivity in hypothyroid rats. Am J Physiol. 1995;268(4 Pt 2):H1428-H1435.

15. Quesada A, Sainz J, Wangensteen R, Rodriguez-Gomez I, Vargas F, Osuna A. Nitric oxide synthase activity in hyperthyroid and hypothyroid rats. Eur J Endocrinol. 2002;147:117-122.

16. Ojamaa K, Klemperer JD, Klein I. Acute effects of thyroid hormone on vascular smooth muscle. Thyroid. 1996;6:505-512.

17. Hiroi Y, Kim HH, Ying H, Furuya F, Huang Z, Simoncini T, Noma K, Ueki K, Nguyen NH, Scanlan TS, Moskowitz MA, Cheng SY, Liao JK. Rapid nongenomic actions of thyroid hormone. Proc Natl Acad Sci U S A. 2006;103:14104-14109.

18. Mullur R, Liu YY, Brent GA. Thyroid hormone regulation of metabolism. Physiol Rev. 2014;94:355-382.

19. Bullock GR, Taylor SG, Weston AH. Influence of the vascular endothelium on agonist-induced contractions and relaxations in rat aorta. Br J Pharmacol. 1986;89:819-830.

20. Kaneko K, Sunano S. Involvement of alpha-adrenoceptors in the endothelium-dependent depression of noradrenaline-induced contraction in rat aorta. Eur J Pharmacol. 1993;240:195-200.

21. Martin W, Furchgott RF, Villani GM, Jothianandan D. Depression of contractile responses in rat aorta by spontaneously released endothelium-derived relaxing factor. J Pharmacol Exp Ther. 1986;237:529-538.

22. Matsuda K, Sekiguchi F, Tojo M, Shimamura K, Sunano S. Effects of NG-nitro-L-arginine on alpha-agonists-induced contraction of aortae from Wistar Kyoto rats and stroke-prone spontaneously hypertensive rats. J Smooth Muscle Res. 1995;31:51-60.

23. Vinet R, Brieva C, Pinardi G, Penna M. Modulation of alpha-adrenergic-induced contractions by endothelium-derived relaxing factor in rat aorta. Gen Pharmacol. 1991;22:137-142.

24. Hunyady L, Catt KJ. Pleiotropic AT1 receptor signaling pathways mediating physiological and pathogenic actions of angiotensin II. Mol Endocrinol. 2006;20:953-970.

25. Guimarães S, Moura D. Vascular adrenoceptors: an update. Pharmacol Rev. 2001;53:319-356.

26. Guibert C, Ducret T, Savineau JP. Voltage-independent calcium influx in smooth muscle. Prog Biophys Mol Biol. 2008;98:10-23.

27. Leung FP, Yung LM, Yao X, Laher I, Huang Y. Store-operated calcium entry in vascular smooth muscle. Br J Pharmacol. 2008;153:846857.

28. Collier ML, Ji G, Wang Y, Kotlikoff MI. Calcium-induced calcium release in smooth muscle: loose coupling between the action poten- 
tial and calcium release. J Gen Physiol. 2000;115:653-662.

29. Nelson MT, Quayle JM. Physiological roles and properties of potassium channels in arterial smooth muscle. Am J Physiol. 1995;268(4 Pt 1):C799-C822.
30. Ratz PH, Berg KM, Urban NH, Miner AS. Regulation of smooth muscle calcium sensitivity: $\mathrm{KCl}$ as a calcium-sensitizing stimulus. Am J Physiol Cell Physiol. 2005;288:C769-C783. 